\title{
CHEMICAL COMPOSITION OF VOLATILE OILS FROM LEAVES OF Nectandra megapotamica SPRENG. (LAURACEAE)
}

Paulete Romoff * e Marcelo J. P. Ferreira

Centro de Ciências e Humanidades, Universidade Presbiteriana Mackenzie, Rua da Consolação, 930, 01302-907 São Paulo - SP, Brasil Ricardo Padilla, Daniela O. Toyama e Oriana A. Fávero

Centro de Ciências Biológicas e da Saúde, Universidade Presbiteriana Mackenzie, Rua da Consolação, 930, 01302-907 São Paulo - SP, Brasil João Henrique G. Lago

Departamento de Ciências Exatas e da Terra, Universidade Federal de São Paulo, Rua Prof. Artur Riedel, 275, 09972-270 Diadema - SP, Brasil

Recebido em 2/9/09; aceito em 14/1/10; publicado na web em 23/4/10

\begin{abstract}
The volatile oils from Nectandra megapotamica Spreng. leaves, collected in February and August of 2007 and at 7:00 and 12:00 h (samples A - D), were extracted by hydrodistillation and the chemical composition was analyzed by GC-FID and GC/MS. A total of nineteen compounds were identified with predominance of oxygenated sesquiterpenes, among them, $\alpha$-bisabolol, was the main constituent (62.3-69.4 $\%)$. After chromatographic separation procedures, this compound was purified from crude oil and its structure was confirmed by analysis of NMR data. This paper describes for the first time the composition of the leaves volatile oil from $N$. megapotamica.
\end{abstract}

Keywords: Nectandra megapotamica; volatile oil composition; $\alpha$-bisabolol.

\section{INTRODUCTION}

As current circumscribed, the Lauraceae family consist of 52 genera and about $2500-3000$ species. This group is widely distributed in the tropical and subtropical regions of the planet, predominantly in Southeast Asia and in Brazil. ${ }^{1}$ Nectandra genus is one of the most representatives of the family and some species have been used in folk medicine as antifungal, antidiarrheal, analgesic and antirheumatic agents. Several investigations have demonstrated the biological activity of certain species of this family, e.g., antitumor activity of $N$. rigida (H.B.K.) Nees, ${ }^{2}$ anti-inflammatory activity of $N$. falcifolia (Nees) Castiglioni ex Martinez C. \& Piccinini ${ }^{3}$ and antimalarial activity of N. cuspidate Nees \& Mart. and N. salicifolia (H.B.K.) Nees. ${ }^{4,5}$ Five species have been studied regarding the volatile oil composition: N. falcifolia (syn. N. angustifolia), ${ }^{6} N$. coriácea (Sw.) Griseb. ${ }^{7} N$. elaiophora Barb. Rodr., ${ }^{8}$ and N. salicina $\mathrm{C}$. K. Allen. ${ }^{9}$

Nectandra megapotamica Spreng., popularly known as "canelalora" or "canela-preta", is a species found in Brazil and used in folk medicine as anti-rheumatic and analgesic. ${ }^{10,11}$ Earlier phytochemical studies have shown the presence of indole alkaloids ${ }^{10}$ as well as antiinflammatory and antichagasic activities of lignoids. ${ }^{12,13}$ Furthermore, recent chemical studies reported the isolation of four phenylpropanoids, one gallic acid derivative, one flavan and one sesquiterpene. ${ }^{14}$

The antitumoral, anti-inflammatory and antimicrobial activities of the volatile oil obtained from $N$. megapotamica also had been previously evaluated, but, the compounds presented in these samples were not reported. ${ }^{15}$ Thus, in continuation of our studies about volatile oils from São Paulo city species, ${ }^{16}$ in this work we report, at first time, the chemical composition of the volatile oils from $N$. megapotamica leaves collected in two distinct months at different hours of a day. Compounds were characterized by GCFID and GC-MS. Additionally, the main constituent present in the volatile oil, the sesquiterpene $\alpha$-bisabolol, through NMR analysis after chromatographic separation procedure.

*e-mail: romoff@mackenzie.br

\section{EXPERIMENTAL}

\section{Plant material}

Leaves of N. megapotamica were collected in São Paulo (São Paulo State, Brazil) in February 15 ${ }^{\text {th }}, 2007$ and August 15 ${ }^{\text {th }}, 2007$ at 7:00 a.m. and 12:00 a.m., totalizing 4 samples (Samples A - D). The botanical identification of the plant was made by Profa. Dra. Oriana A. Fávero and a voucher sample (No. IF-SPSF 39648) was deposited in the Herbarium of Florestal Institute of São Paulo, São Paulo, Brazil.

\section{Volatile oil extraction}

For each collection, the fresh leaves of N. megapotamica were submitted to hydrodestillation extraction in Clevenger apparatus during $4 \mathrm{~h}$. The volatile oils were extracted with $\mathrm{CH}_{2} \mathrm{Cl}_{2}$, dried over anhydrous $\mathrm{Na}_{2} \mathrm{SO}_{4}$, and filtered. After evaporation of solvent, the yield of each oil was calculated based in weight of fresh leaves.

\section{Volatile oil analysis and identification of constituents}

The volatile oils were analyzed by GC (Hewlett-Packard 5890 series II) equipped with a FID-detector, using a HP-5 capillary column (30 $\mathrm{m} \times 0.32 \mathrm{~mm} \times 0.25 \mu \mathrm{m})$, an automatic injector (HP 7673) and an electronic integrator (HP 3396A). These analyses were done injecting $1.0 \mu \mathrm{L}$ of a solution at $1.0 \mathrm{mg} / \mathrm{mL}$ of volatile oil in $\mathrm{CH}_{2} \mathrm{Cl}_{2}$ in a split mode (1:30). Injector and detector temperatures were set at 220 and $280{ }^{\circ} \mathrm{C}$, respectively. The oven temperature was programmed from $60-280{ }^{\circ} \mathrm{C}$ at $3{ }^{\circ} \mathrm{C} / \mathrm{min}$, keeping $10 \mathrm{~min}$ at $280^{\circ} \mathrm{C}$ in the end of analysis and helium was employed as carrier gas $(1 \mathrm{~mL} / \mathrm{min})$ for all analyses. The percentage compositions of the oil samples were computed from the GC peak areas without using correction for response factors.

The sample was analyzed by GC-MS, using a Hewlett-Packard 6890 chromatograph and coupled with a Hewlett-Packard 5973 spectrometer operating at $70 \mathrm{eV}$, at the same conditions as described above. The identification of the individual compounds was performed by comparison of both Kovat's retention indexes (determined relati- 
vely to the retention times of a series of n-alkanes) and mass spectra with those available in the system. ${ }^{17}$

\section{Main component isolation and identification}

The volatile oil (1.62 g) from N. megapotamica leaves (Sample C) was subjected to $\mathrm{CC}$ on silica gel eluted with $\mathrm{CH}_{2} \mathrm{Cl}_{2}(100 \mathrm{~mL})$ and $\mathrm{CH}_{2} \mathrm{Cl}_{2} / \mathrm{MeOH}$ mixtures of increasing polarities [99:1 (100 mL), 98:2 $(50 \mathrm{~mL})$ and 9:1 $(50 \mathrm{~mL})$, respectively] to afford 44 fractions. These fractions were analyzed by TLC and pooled into four groups $\left(\mathrm{G}_{1}-\mathrm{G}_{4}\right)$. From $\mathrm{G}_{2} 1.18 \mathrm{~g}$ of $\alpha$-bisabolol was obtained with $99.7 \%$ purity $(\mathrm{GC})$.

The ${ }^{13} \mathrm{C}$ and DEPT $135^{\circ} \mathrm{NMR}$ spectra of this compound were registered at $75 \mathrm{MHz}$ into a Bruker spectrometer (DPX-300 model) using $\mathrm{CDCl}_{3}$ as solvent.

\section{RESULTS AND DISCUSSION}

The yields, the chemical composition, and the relative percentages of constituents found in the volatile oils obtained from the samples A, B, $\mathrm{C}$, and D of N. megapotamica leaves are shown in Table 1. The yields, calculated on basis of weight of fresh leaves, were determined as 0.11$0.18 \%$, similar to the volatile oil obtained from fresh leaves of N. salicina. ${ }^{9}$

Table 1. Chemical composition yields of volatile oil from Nectandra megapotamica leaves in each collection period

\begin{tabular}{|c|c|c|c|c|c|}
\hline Components & KI & Sample A & Sample B & Sample C & Sample D \\
\hline$\alpha$-Pinene & 939 & 0.2 & 0.1 & 3.3 & 2.0 \\
\hline Camphene & 953 & - & - & 0.3 & 0.2 \\
\hline$\beta$-Pinene & 980 & 0.9 & 0.4 & 4.2 & 3.1 \\
\hline$\beta$-Myrcene & 991 & - & - & 0.1 & 0.1 \\
\hline Limonene & 1031 & 0.9 & 0.5 & 1.4 & 0.1 \\
\hline Safrole & 1285 & 1.6 & 1.3 & 0.4 & 0.4 \\
\hline$\delta$-Elemene & 1339 & 16.2 & 8.2 & 22.6 & 22.5 \\
\hline$\beta$-Elemene & 1391 & - & 1.6 & - & - \\
\hline$\gamma$-Elemene & 1433 & - & 0.2 & - & - \\
\hline$\beta$-Farnesene & 1458 & 0.1 & 0.2 & - & - \\
\hline Allo-aromadendrene & 1461 & 0.2 & 0.4 & - & - \\
\hline Germacrene D & 1480 & 0.3 & - & - & 0.1 \\
\hline Bicyclogermacrene & 1494 & 0.8 & 0.9 & - & - \\
\hline$\alpha$-Muurolene & 1499 & - & 0.4 & - & - \\
\hline$\beta$-Bisabolene & 1504 & 0.1 & 0.5 & - & 0.2 \\
\hline Elemol & 1549 & 1.5 & - & - & 0.9 \\
\hline Nerolidol & 1564 & 0.9 & 0.9 & 0.3 & 0.5 \\
\hline Spathulenol & 1576 & 0.2 & - & - & 0.2 \\
\hline$\alpha$-Bisabolol & 1683 & 67.7 & 69.4 & 64.8 & 62.3 \\
\hline \multicolumn{2}{|l|}{ Monoterpenoids } & 2.0 & 1.0 & 9.3 & 5.5 \\
\hline \multicolumn{2}{|c|}{ Hydrocarbon sesquiterpenoids } & 17.7 & 12.4 & 22.6 & 22.8 \\
\hline \multicolumn{2}{|c|}{ Oxygenated sesquiterpenoids } & 70.3 & 70.3 & 65.1 & 63.9 \\
\hline \multicolumn{2}{|l|}{ Terpenoids } & 90.0 & 83.7 & 97.0 & 92.2 \\
\hline \multicolumn{2}{|l|}{ Phenylpropanoid } & 1.6 & 1.3 & 0.4 & 0.4 \\
\hline \multicolumn{2}{|c|}{ TOTAL } & 91.6 & 85.0 & 97.4 & 92.6 \\
\hline \multicolumn{2}{|c|}{ Yield / \% } & 0.11 & 0.18 & 0.14 & 0.17 \\
\hline
\end{tabular}

Sample A (February 7:00 a.m.), Sample B (February 12:00 a.m.), Sample C (August 7:00 a.m.), Sample D (August 12:00 a.m.).

The identification of volatile derivatives was carried out by automated interpretation of mass spectra of constituents in each analyzed oil and also by retention index. A total of nineteen derivatives - monoterpenes, sesquiterpenes and phenylpropanoid - were characterized, corresponding to $85.0-97.4 \%$ of the identified derivatives.
The occurrence of phenylpropanoids in N. megapotamica was reported previously, ${ }^{14}$ in which elemicin and isoelemicin were detected from stem bark. However, in the present work, only a reduced relative amount (1.3-1.6\%) of one $\mathrm{C}_{6} \mathrm{C}_{3}$ derivative, safrole, was found in the volatile oil from leaves in February, being lower in August samples $(0.4 \%)$.

Other eighteen components, among them mono and sesquiterpenes, were identified in the volatile oils corresponding to 83.7-97.0\% of the samples (Table 1). In the August collections, five monoterpenes ( $\alpha$-pinene, camphene, $\beta$-pinene, $\beta$-myrcene and limonene) were detected corresponding to $5.5-9.3 \%$ of the volatile oils. Otherwise, in February collections only the monoterpenes $\alpha$-pinene, $\beta$-pinene and limonene were identified corresponding to $1.0-2.0 \%$ of the oils. However, if a higher diversification in the skeleton of monoterpenes was detected in August in comparison to February collections, the opposite was observed to sesquiterpenes, since only seven $\mathrm{C}_{15}$ derivatives were identified in the samples $C$ and $D$.

Regarding the percentage of sesquiterpenes, was observed a small variation in the ratio of these components $(82.7-88.0 \%)$ being $\delta$-elemene (8.2-22.6\%) and $\alpha$-bisabolol (62.3-69.4\%) the main constituents in all samples. However, when comparing the content of hydrocarbon $\mathrm{x}$ oxygenated sesquiterpenes, there is a greater accumulation (70.3\%) of oxygenated derivatives in both February samples A and B (7:00 and 12:00 a.m.) in comparison to August collections C and D (63.9-65.1\%). In August, a decrease in the content of oxygenated derivatives is observed with consequent increase in total of sesquiterpene hydrocarbons. The highest percentage of non-oxygenated sesquiterpenes has not been accompanied by structural diversification once only $\delta$-elemene, $\beta$-bisabolene, and germacrene $\mathrm{D}$ were detected in the samples. Comparatively, the volatile oils from other Nectandra species showed to be composed mainly by monoterpenes $[N$. falcifolia $^{6}$ - mentha-1(7),8-diene (25.2\%), $\alpha$-terpinolene $(20.9 \%)$, and $\alpha$-pinene $(10.0 \%) ; N$. elaiophora ${ }^{8}-\alpha$-pinene (35\%), $\beta$-pinene $(20 \%)$, and $\alpha$-terpineol $(12 \%)]$ and sesquiterpenes $\left[N\right.$. coriacea ${ }^{7}-$ valerianol $(16.7 \%)$ and $\gamma$-eudesmol $(12.3 \%)$; N. salicina ${ }^{9}$ - atractylone (leaves: $14.6 \%$, stems: $21.1 \%$ ), viridiflorene (leaves: $10.1 \%$, stems: $7.9 \%$ ), and germacrene D (leaves: 5.8\%, stems: 10.7\%)]. However, the occurrence of $\alpha$-bisabolol as major derivative was not reported in the previous volatile oils from Nectandra species.

Finally, the high concentration of $\alpha$-bisabolol in the volatile oils from $N$. megapotamica leaves had led us to the isolation of the compound by chromatographic column separation, aiming the identification of this constituent by NMR techniques. The ${ }^{13} \mathrm{C}$ and DEPT $135^{\circ} \mathrm{NMR}$ spectra of pure derivative showed four signals corresponding to $\mathrm{sp}^{2}$ carbons at $\delta 133.7(\mathrm{C}), 131.1(\mathrm{C}), 124.5\left(\mathrm{CH}_{2}\right)$, and $120.4\left(\mathrm{CH}_{2}\right)$, one carbinolic carbon at $\delta 74.0(\mathrm{C})$, as well as four methyl groups at $\delta 25.5\left(2 \mathrm{X} \mathrm{CH}_{3}\right), 17.4\left(\mathrm{CH}_{3}\right)$, and $23.1\left(\mathrm{CH}_{3}\right)$. The comparison of the obtained spectral data with those reported in the literature, confirmed the structure of $\alpha$-bisabolol. ${ }^{18}$

\section{CONCLUSION}

This work reports, at first time, the chemical composition of volatile oils obtained from leaves of $N$. megapotamica. It was observed that $\alpha$-bisabolol was the major component encountered, without seasonal and circadian variation in all analyzed samples. Considering the studied volatile oils from other Nectandra species it can be observed a dichotomy in relation to production of chemical constituents, i.e. monoterpenes or sesquiterpenes enriched oils. N. megapotamica belongs to the second group because the major components are sesquiterpenoids. However, a comparison with literature data does not allow verifies a preferential accumulation of a specific $\mathrm{C}_{15}$ skeleton carbonic in the genus. Further investigations should be carried out 
with other specimen to verify the influence of environmental conditions and/or microclimatic factors in the production/accumulation of volatile derivatives. ${ }^{19}$

\section{ACKNOWLEDGMENTS}

The authors are grateful to financial support from MACKPESQUISA, CNPq and FAPESP.

\section{REFERENCES}

1. Cronquist, A.; An integrated system of classification of flowering plants, Columbia University: New York, 1962.

2. Le Quesne, P. W.; Larrahondo, J. E.; Raffauf, R. F.; J. Nat. Prod. 1980, $43,353$.

3. Melo, J. O.; Truitti, M. C. T.; Muscará, M. N.; Bolonheis, S. M.; Dantas, J. A.; Caparroz-Assef, S. M.; Cuman, R. K. N.; Bersani-Amado, C. A.; Biol. Pharm. Bull. 2006, 29, 2241.

4. Muñoz, V.; Sauvain, M.; Bourdy, G.; Callapa, J.; Bergeron, S.; Roj, I.; Bravo, J. A.; Balderrama, L.; Ortiz, B.; Gimenez, A.; Deharo, E.; J. Ethnopharmacol. 2000, 69, 127.

5. Bohlke, M.; Guinaudeau, H.; Angerhofer, C. K.; Wongpanich, V.; Soerjato, D. D.; Farnsworth, N. R.; J. Nat. Prod. 1996, 59, 576.

6. Torres, A. M.; Ricciardi, G. A. L.; Agrelo de Nassif, A. E.; Ricciardi, A. I. A.; Dellacassa, E.; Comunicaciones Científicas y Tecnológicas, Universidad Nacional de Nordeste, Argentina, 2005, Resumen E-013, http://www.unne. edu.ar/Web/cyt/com2005/index.htm, accessed on April 2010.
7. Marbot, R.; Pino, J. A.; Paya, A.; Chao, D.; Herrera, D.; J. Essent. Oil Res. 2005, 17, 648.

8. Naves, Y. R.; Bull. Soc. Chim. Fr. 1951, 987.

9. Cicció, J. F.; Chaverri, C.; Díaz, C.; Quim. Nova 2009, 32, 417.

10. Santos Filho, D.; Gilbert, B.; Phytochemistry 1975, 14, 821.

11. Novaes, A. C.; Silva, M. L. A.; Bastos, J. K.; Rev. Bras. Farm. 1998, 79, 17.

12. Silva, A. A.; Albuquerque, S.; Silva, M. L. A.; Eberlin, M. N.; Tomazela, D. M.; Bastos, J. K.; J. Nat. Prod. 2004, 67, 42.

13. Silva, A. A.; Silva, M. L. A.; Carvalho, J. C. T.; Bastos, J. K.; J. Pharm. Pharmacol. 2004, 56, 1179.

14. Garcez, F. R.; Garcez, W. S.; Hamerski, L.; Miguita, C. H.; Quim. Nova 2009, 32, 407

15. Apel, M. A.; Lima, M. E. L.; Souza, A.; Cordeiro, I.; Young, M. C. M.; Sobral, M. E. G.; Suffredini, I. B.; Moreno, P. R. H.; Pharmacol. Online 2006, 3, 376 .

16. Lago, J. H. G.; Romoff, P.; Fávero, O. A.; Soares, M. G.; Baraldi, P. T.; Corrêa, A. G.; Souza, F. O.; Quim. Nova 2008, 31, 727.

17. Adams, R. P.; Identification of essential oil components by gas chromatography/ quadrupole mass spectrometry, Academic Press: San Diego, 1995.

18. Carle, R.; Beyer, J.; Cheminat, A.; Krempp, E.; Phytochemistry 1992, 31,171 .

19. Gobbo-Neto, L.; Lopes, N. P.; Quim. Nova 2007, 30, 374. 